\section{Mundo Revista de} agrario estudios rural
Mundo Agrario, agosto 2018, vol. 19, n 41, e084. ISSN 1515-5994

Universidad Nacional de La Plata

Facultad de Humanidades y Ciencias de la Educación

Centro de Historia Argentina y Americana

\title{
Transformaciones en la agricultura de los mayas peninsulares: Un contraste de los casos de Kampocolché y Xohuayán
}

\author{
Lilia Betania Vázquez González \\ El Colegio de la Frontera Sur, México \\ Ibetania.vazquez@gmail.com \\ Manuel Roberto Parra Vázquez \\ El Colegio de la Frontera Sur, México \\ mparra@ecosur.mx \\ María Amalia Gracia \\ El Colegio de la Frontera Sur, México \\ magracia@ecosur.edu.mx
}

Cita sugerida: Vázquez González, L. B., Parra Vázquez, M. R. y Garcia, M. A. (2018). Transformaciones en la agricultura de los mayas peninsulares: Un contraste de los casos de Kampocolché y Xohuayán. Mundo Agrario, 19(41), e084. https://doi.org/10.24215/15155994e084

Recibido: 24 de Octubre 2017 - Aceptado: 14 de Julio 2018 - Publicado: 15 Agosto de 2018

(c) (1) (2) (2) Esta obra está bajo licencia Creative Commons Atribución-NoComercial-CompartirIgual 4.0 Internacional cc) 


\section{Transformaciones en la agricultura de los mayas peninsulares: Un contraste de los casos de Kampocolché y Xohuayán}

Changes on Mayans agriculture in the Yucatan Peninsula: A contrast between two study cases, Kampocolche and Xohuayan

Lilia Betania Vázquez González

El Colegio de la Frontera Sur, México

lbetania.vazquez@gmail.com

Manuel Roberto Parra Vázquez

El Colegio de la Frontera Sur, México

mparra@ecosur.mx

Maria Amalia Gracia

El Colegio de la Frontera Sur, México

magracia@ecosur.edu.mx

\section{RESUMEN:}

El objetivo es analizar de qué forma las intervenciones nacionales e internacionales interactúan con los modos de vida y en las actividades agropecuarias de los campesinos mayas. Desde un enfoque constructivista y utilizando técnicas de metodología cualitativa contrastamos dos estudios de caso; en una comunidad los campesinos mantienen su organización comunitaria y las prácticas agrícolas tradicionales que les permiten el autoabastecimiento y el manejo común de sus recursos naturales; en otra, las intervenciones generaron cambios observables en el manejo del territorio, el calendario agropecuario y la organización comunitaria, aceptando la modernización y atendiendo las demandas del mercado.

Palabras Clave: Agricultura, Resistencia, Intervención pública, Campesinado, Mayas.

\section{ABstraCT:}

This article analyzes how international interventions interact with livelihoods and agricultural practices of Mayan peasants. We use qualitative methodology and constructivism approach in two contrasting studying cases in Yucatan peninsula, both are Mayan communities. In first community the peasants resist, through the preservation of community organization, traditional agricultural practices that provide them with consumption assets (not cash) and the common management of their natural resources. In the second community, interventions affected the territorial appropriation, agricultural activities and the community organization, by accepting modernization and market demands.

KEYWORDS: Agriculture, Resistance, Public intervention, Peasants, Mayas.

\section{INTRODUCCIÓN}

El pensamiento convencional del desarrollo ha considerado a la industrialización como base del progreso de todas las naciones, lo cual demanda la instauración de los valores mercantiles en las personas (Escobar, 1995) y supone la imposición de un modelo externo para mantener el control social (colonialidad). Existen experiencias de resistencia a la colonialidad aglutinadas en torno a conceptos como el etnodesarrollo, noción que involucra a los propios grupos étnicos en el trazado de proyectos que incluyen sus propios recursos materiales, valores y aspiraciones comunitarias, y su experiencia histórica pensada como recurso potenciador de los proyectos (Bonfil, 1995).

Bajo el cobijo de diferentes corrientes desarrollistas, en el último tercio del siglo XX se instalaron en las comunidades rurales diferentes proyectos con el argumento de contribuir al mejoramiento de la vida de los campesinos. A partir de enfoques desarrollistas, indigenistas y más recientemente ambientalistas, los proyectistas se inmiscuyeron tan estrechamente en la vida de los campesinos que modificaron la construcción de sus proyectos a futuro. Pocas veces los proyectistas alcanzan a comprender los cambios que se generan en 
las lógicas de los campesinos y en sus modos de vida a partir de intervenciones cuyo propósito es alcanzar el desarrollo occidental.

A partir de lo anterior, y considerando que los campesinos mayas no son sujetos pasivos, nos preguntamos sobre las formas en que las intervenciones han modificado sus sistemas agrícolas y pecuarios, y sobre las repercusiones que tienen estos cambios en sus modos de vida.

A partir de lo anterior, y considerando que los campesinos mayas no son sujetos pasivos, nos preguntamos sobre las formas en que las intervenciones han modificado sus sistemas agrícolas y pecuarios, y sobre las repercusiones que tienen estos cambios en sus modos de vida.

A partir de este interrogante seleccionamos dos casos de estudio por sus particularidades en el contexto regional a fin de entender, a partir de dos modelos de desarrollo contrastantes, los cambios en la lógica y vida campesina. El primer caso es una comunidad en la zona maya de Quintana Roo cuyos medios de producción están orientados principalmente al autoabasto y mantienen una forma de vida tradicional, mientras que el segundo caso, ubicado en el sur del estado de Yucatán, muestra familias que han transitado una estrategia productiva diversificada, modificando sus formas de producción y su subjetividad para adaptarse al mercado. En ambos modelos se analizan de forma integral los resultados de variadas intervenciones estratégicas y las decisiones de los productores bajo políticas de desarrollo rural y ambiental diferentes.

Las intervenciones en las comunidades también han sido distintas debido a las políticas estatales de cada cual. La deforestación en el estado de Yucatán ha sido mayor que en centro de Quintana Roo, debido a que en el primero se ha incentivado la ganadería y la agricultura, mientras que en el segundo la agricultura itinerante permite un tiempo suficiente de recuperación, cuyos beneficios van aunados al manejo forestal comunitario, el ecoturismo y el potencial de productos maderables (Ellis, Hernández y Romero, 2017). En la zona maya de Quintana Roo se ejecutó el plan piloto forestal durante los recientes ochenta, el cual brindaba capacitación a los ejidatarios sobre el manejo de la selva con el propósito de hacer un manejo forestal sustentable, pues previo a esta época la extracción de maderas preciosas para la fabricación de durmientes para las vías de ferrocarril se extendió en esta zona (Ellis \& Porter, 2008).

Es entre 1970 y 1990 que el crecimiento económico de Quintana Roo se incrementa como resultado de la activación de sus centros turísticos, en especial de la ciudad de Cancún, de tal manera que el principal eje del desarrollo en este estado ha sido la inversión en turismo a gran escala, la cualimpulsa a los jóvenes de las comunidades a desplazarse (Baños, 2001). En cambio el estado de Yucatán se orientó desde 1950 a la producción agrícola.Durante esa época se dedicó al monocultivo de henequén, que disminuyó su aportación al PIB (Producto Interno Bruto) de tal forma que para 1983 la misma era de 5,9\%. Esto significó que entre 1970 y 1990 el estado otorgara subsidios a diversas actividades agropecuarias. Ejemplo de esto fue el intento de activar la citricultura, que no resultó rentable. En la reciente década, la política en Yucatán cambió y el mayor aporte al PIB estatal lo ocupan los servicios y la maquiladora (Baños, 2001).

\section{Marco teórico-CONCEPTUAL}

Las intervenciones son procesos creadores de significados que involucran discursos dominantes promotores de puntos de vista políticos, culturales y morales. A menudo estos procesos son reformados por las respuestas, estrategias y dinámicas internas organizacionales, culturales y políticas de los grupos locales que luchan por definir y defender sus espacios sociales y fronteras culturales (Long, 2007). Desde los años setenta las políticas públicas han involucradointervenciones que siguen modelos escalonados y lineales para obtener determinados resultados y, al igual que en otras partes del mundo, en la península de Yucatán inciden sobre grupos étnicos. Éstos son conglomerados sociales con rasgos culturales propios y capacidad para reproducirse a sí mismos (Bonfil, 1991) y con modos de vida definidos, es decir, con un conjunto de rasgos y procederes particulares que determinan su devenir en el tiempo. Los modos de vida de los grupos étnicos hacen referencia a cuatro componentes interrelacionados: la cultura y las subjetividades, sus necesidades y anhelos (materiales 
e inmateriales), sus estrategias productivas y los medios o capitales con los que cuentan para llevar a cabo cada estrategia. Es en los modos de vida donde las intervenciones tienen un rol determinante en la transformación de la subjetividad de los grupos étnicos, porque existe una tensión continua entre los procesos creadores de nuevos significados y la lucha por mantener las estructuras propias.

El análisis de las subjetividades de los campesinos -entendidas como el conjunto de sentimientos, creencias, valores, actitudes y motivaciones que conducen al sujeto a construir su propia realidad de forma individual o colectiva- nos permite comprender las transformaciones en sus modos de vida y en la apropiación territorial, entendida ésta como la forma en la que proyectan sus propias reglas de organización sobre los recursos, sus posibles usos, el acceso y control, y la forma en que se transfieren los derechos de acceso (Weber y Reverte, 2006).

Los discursos de las intervenciones modifican la subjetividad de los campesinos y transforman su relación con el entorno, lo cual conduce a un proceso moderno de colonialidad. Ésta refiere a la forma en que aspectos como el trabajo, el conocimiento y las relaciones intersubjetivas se articulan a partir del mercado; es la inclinación de las formas de producción material y subjetiva acorde a los dictados de la cultura occidental (Marañón, 2012; Waldmueller, 2015). De esta manera, las intervenciones actúan como nuevas y efectivas estrategias por medio de las cuales la colonialidad ocurre en poblaciones dominadas. En este caso nos referimos a los grupos indígenas de quienes se espera cambien su modo de vida y transformen su comportamiento para que puedan adaptarse al mercado, subordinados a las instituciones financieras que poseen capital económico, tecnología y conocimiento científico para dicha adaptación.

La racionalidad-modernidad es la herramienta que sirve como mecanismo para mantener la colonialidad (Mignolo, 2005), ya que la cultura occidental sólo admite determinado tipo de racionalidad, en especial el conocimiento aprobado científicamente que permite el alcance de la modernidad, y consecuentemente desprecia el conocimiento tradicional que no ha pasado por esa comprobación. Así, la cultura occidental se convierte en una forma de acceso al poder (Quijano, 1992) y los campesinos se dan cuenta de ello, por lo que en determinados casos deciden transitar hacia ella de manera paulatina.

Estas transformaciones toman relevancia en la agricultura, porque es un sector estratégico para los modelos de desarrollo en todo el mundo, de tal forma que los planes para modernizarla han estado marcados a lo largo de los años por medio de diferentes acciones del gobierno. Muestra de ello es la política estadunidense que ha logrado imponer sus procesos agrícolas en el mundo-que incluyen el uso de fertilizantes químicos y pesticidas, la extracción de grandes volúmenes de agua y la dependencia de energía fósil-,los cuales inducen a la contaminación del agua, la erosión del suelo y la degradación de los recursos (Graddy-Lovelace, 2017; Waldmueller, 2015).

En este trabajo analizamos en sus modos de vida campesinos dos comunidades con posiciones diferentes frente a las intervenciones. Así, los campesinos en Kampocolché desarrollan prácticas de resistencia con las que intentan mantener el control de elementos propios que les dan identidad con el propósito de preservar su cultura autónoma (Bonfil, 1991), prácticas que podemos observar en el mantenimiento del cultivo de la milpa tradicional, el uso comunitario de los recursos naturales y la subjetividad en relación a la cría de cerdos destinados a los festejos religiosos. Para hacer más visible este proceso lo contrastamos con Xohuayán, donde los modos de vida fueron transformados con el abandono del cultivo de la milpa y el paso al cultivo mecanizado del maíz, la parcelación del territorio y laadaptación al mercado de productos agrícolas y pecuarios.

\section{Metodología}

El estudio se realizó en el sureste de México, territorio de indígenas mayas donde se ubican las comunidades

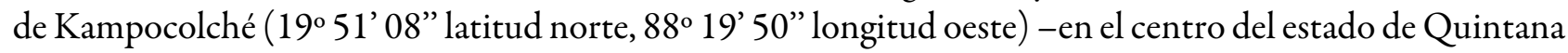
Roo- y la comunidad de Xohuayán (20 11' 14" latitud norte, 8922'59” longitud oeste) en el sur del 
estado de Yucatán (Figura 1). Estas comunidades se seleccionaron para contrastar diferentes objetivos de producción y estrategias para alcanzarlos.

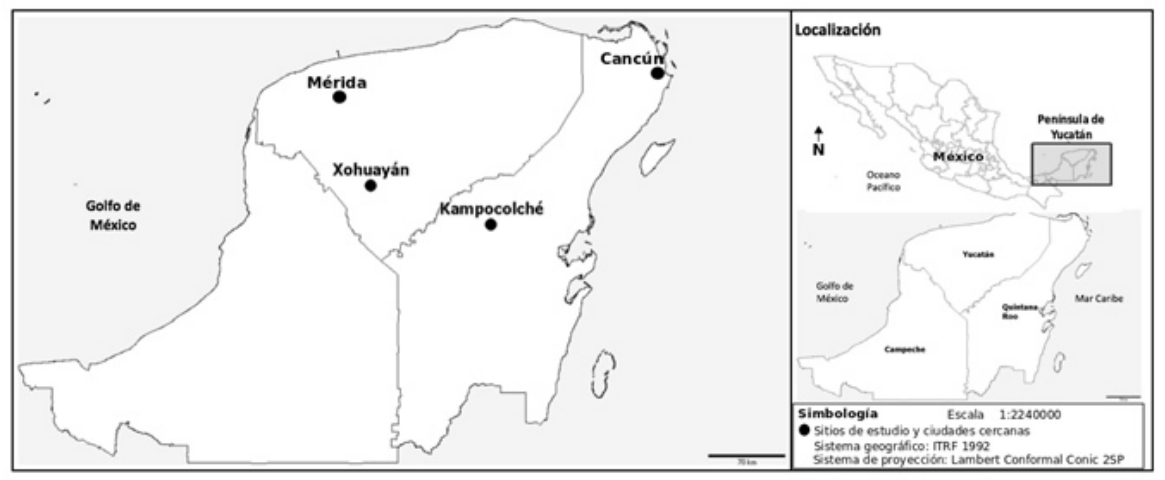

Figura 1. Mapa de localización de las comunidades de estudio

Fuente: Elaborado con datos del INEGI (2010)

Las técnicas utilizadas fueron entrevistas semiestructuradas y talleres participativos, realizados entre mayo de 2015 y septiembre de 2016. En Kampocolché seleccionamos un grupo de ejidatarios representativos de esa comunidad y ejidos aledaños, mientras que en Xohuayán las entrevistas se realizaron a miembros de una cooperativa que ha sido un grupo líder en la comunidad, que ha recibido intervenciones en reiteradas ocasiones, y cuyas acciones han sido replicadas por otros campesinos de la comunidad. Tanto las entrevistas como los talleres participativos permitieron obtener la siguiente información:

1. Distinción de unidades territoriales. A partir de una dinámica y un mapa que incluía la totalidad del territorio de las comunidades, los participantes señalaron áreas caracterizadas porla aplicación de diferentes estrategias productivas acordes a las propiedades del territorio y poruna organización social apropiada para desarrollarlas. Las unidades para Kampocolché fueron el monte de los abuelos (>30 años) - “monte" es la denominación común de los campesinos a la selva-, el monte alto (10-15 años), la milpa, el hubché (vegetación secundaria que aparece como etapa de sucesión entre la milpa y el monte alto) y el potrero, mientras que para Xohuayán fueron la milpa, el maíz mecanizado, los frutales, los potreros y el monte alto (10-15 años).

2. Cambios temporales en las unidades territoriales. Con una dinámica grupal, los campesinos reconstruyeron los cambios en el uso del suelo, desde 1950 a 2016 en Kampocolché, y desde 1988 a 2015 en Xohuayán. Las diferencias en temporalidad responden a la diferencia en las políticas explicadas en el apartado anterior, ya que en la primera comunidad el manejo de la selva es un elemento más relevante y se remonta a varias generaciones previas. En cambio, en el sur de Yucatán el giro en el modo de vida ocurre a partir de la reciente década de los ochenta.

3. Calendario agropecuario. Los campesinos describieron las actividades que realizan mes a mes y las temporadas más y menos benéficas para ellos.

4. Las instituciones relevantes en la comunidad. Se determinaron las dependencias gubernamentales, organizaciones de la sociedad civil, programas, proyectos y partidos políticos que generaron procesos de cambio en la comunidad.

5. Ingresos obtenidos en las actividades agrícolas dirigidas al mercado y los beneficios económicos derivados de la milpa, principal sistema agrícola de autoconsumo para los mayas.

En Kampocolché participaron 12 ejidatarios en los talleres y entrevistas, todos ellos varones de entre 40 y 70 años de edad, y en Xohuayán fueron diez campesinos varones no ejidatarios de entre 40 y 60 años de edad. 


\section{LA APROPIACIÓN TERRITORIAL EN KAMPOCOLCHÉ}

La comunidad de Kampocolché posee elementos culturales autónomos que le han permitido mantener las decisiones colectivas y comunitarias que regulan el manejo de los recursos materiales en la comunidad, así como sus formas de organización. Es el caso de los rumbos - caminos hacia las milpas tradicionales y a los apiarios- conformados poráreas de vegetación secundaria, y transformados por los grupos domésticos de la comunidad.Cada rumbo pertenece a grupos de parentesco patrilineales y esheredable de generación en generación (Estrada, Bello y Velazco, 2011).

La producción de la milpa tradicional ${ }^{1}$ implica la apropiación histórica del territorio con base en derechos familiares heredados. Estas relaciones van más allá de la producción de la milpa, pues entre los grupos familiares también celebran rituales agrícolas (Estrada, Bello y Velazco, 2011), elementos culturales indisociables de la identidad maya. Si bien cada familia campesina toma decisiones dentro de su milpa y apiarios, es necesario el consenso previo con otros campesinos para situar a ambos. Esta organización forma parte del patrimonio cultural heredado y mantenido durante años en comunidades mayas en las que persiste el cultivo de la milpa tradicional. Además, las autoridades líderes no son únicamente las establecidas por el gobierno mexicano en cualquiera de sus jurisdicciones, sino que mantienen el sistema de cargos comunitarios en el que gobiernan los ancianos nombrados por la comunidad.

La resistencia en esta comunidad se expresa en la apropiación territorial, en las formas de organización y en los procesos productivos y reproductivos.Un ejemplo de ello se aprecia en la distribución de las milpas y en la organización por rumbos (en la figura 1 las líneas centrales (D) representan los rumbos). En el ejido de Kampocolché la Comisión Nacional para el Conocimiento y Uso de la Biodiversidad (conabio) identificó cuatro áreas de conservación voluntaria (Figura 2), no certificadas y no sujetas a pagos por servicios ambientales $^{2}$, que en conjunto suman el $11,6 \%$ de su superficie (Elizondo y López, 2009). La reserva más antigua tiene una superficie de 220,85 ha y corresponde al "monte de los abuelos" -territorio denominado así por sus habitantes-, el cual se mantiene bajo normas comunitarias de no talar pero se beneficia con la recolecta de herbáceas y de la apicultura.

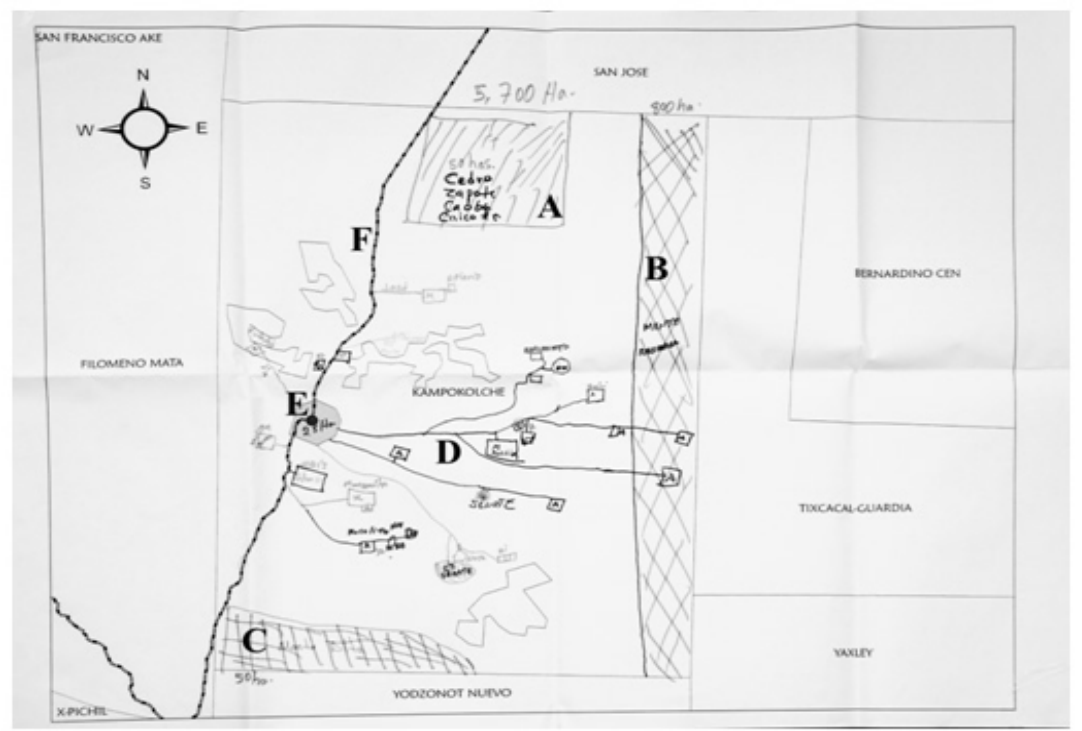

(A) área reforestada; (B y C) áreas de conservación voluntaria; (D) "Rumbos": caminos para llegar a su milpa y apiarios; (E) zona urbana; $(F)$ caminos de acceso a la comunidad.

Figura 2. Unidades territoriales utilizadas en Kampocolché, Quintana Roo según los propios campesinos 
En la figura 3 observamos los cambios en el territorio a lo largo de los años. En 1950 el territorio lo ocupaba principalmente el monte de los abuelos y en menor parte la milpa, pero debido a un incendio, en 1960 el monte alto se redujo drásticamente hasta quedar principalmente monte alto y milpa. Posteriormente reconocen un área de hubché de la cual también se beneficia la cría de abejas. En 1990 los campesinos redujeron el monte alto para dar lugar a potreros con pasto para bovinos. En 10 años esta unidad aumentó, sin embargo, en 2010 la comunidad convino evitar la producción de rumiantes, lo que fomentó la recuperación del monte alto. Para 2016 la mayor parte del territorio la ocupaba la vegetación secundaria, seguida de la milpa y en una menor proporción el monte alto y la reserva (monte de los abuelos).

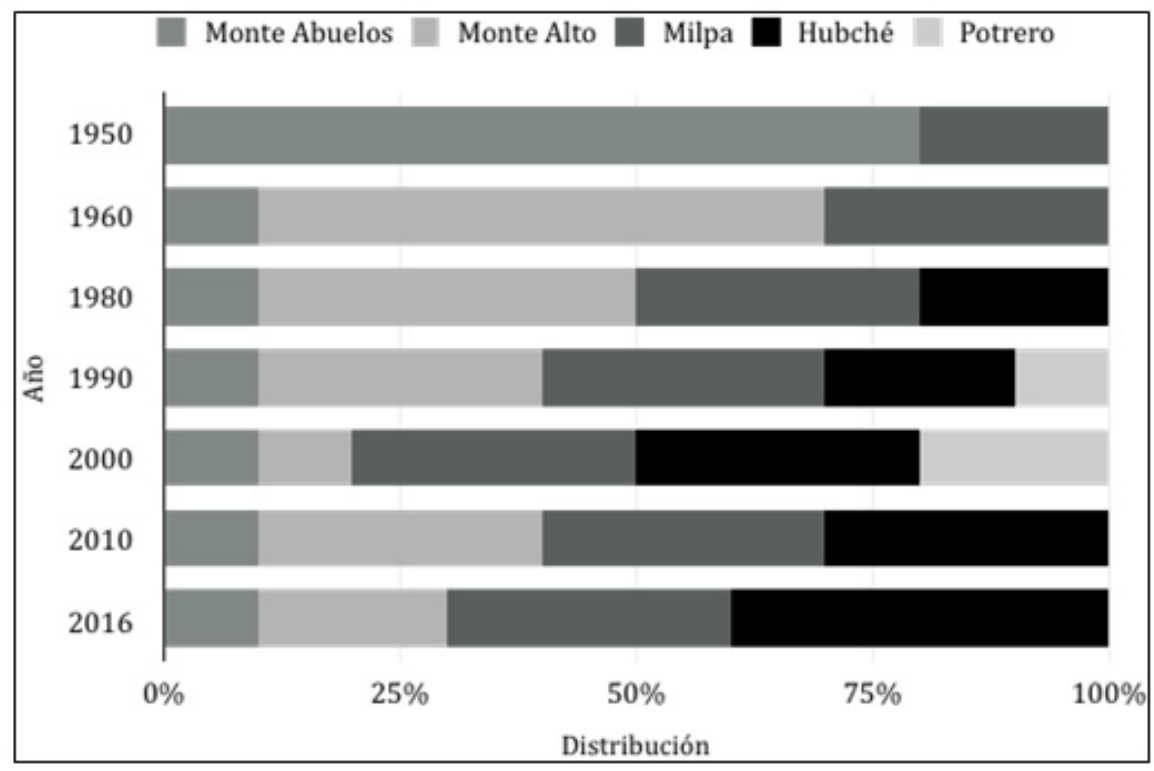

Figura 3. Cambios en la distribución de las unidades territoriales de Kampocolché según los propios campesinos (1950-2016)

Fuente: Elaboración propia

Estas prácticas nos hablan de una estrategia de usos múltiples de la que participan varios sistemas productivos con sus componentes interrelacionados entre sí. Así, mientras sus unidades territoriales les proporcionan alimento, la apicultura les proporciona dinero en efectivo (Figura 4). Esta dependencia de ingresos proveniente de la miel, induce actividades de conservación de la selva, pues como se observa en la figura 3, en la década de 1990 incursionaron en la producción de rumiantes, y aumentaron la superficie de potreros, pero esa actividad luego la abandonaron. Esto se debió a que la incorporación de potreros requería cercado y definición de propiedad de los terrenos, lo cual se oponía al acuerdo que rige entre los campesinos. Asimismo, esto reducía el monte alto y la vegetación secundaria, áreas de pecoreo de las abejas y la consiguiente reducción del número de colmenas de los ejidatarios. 


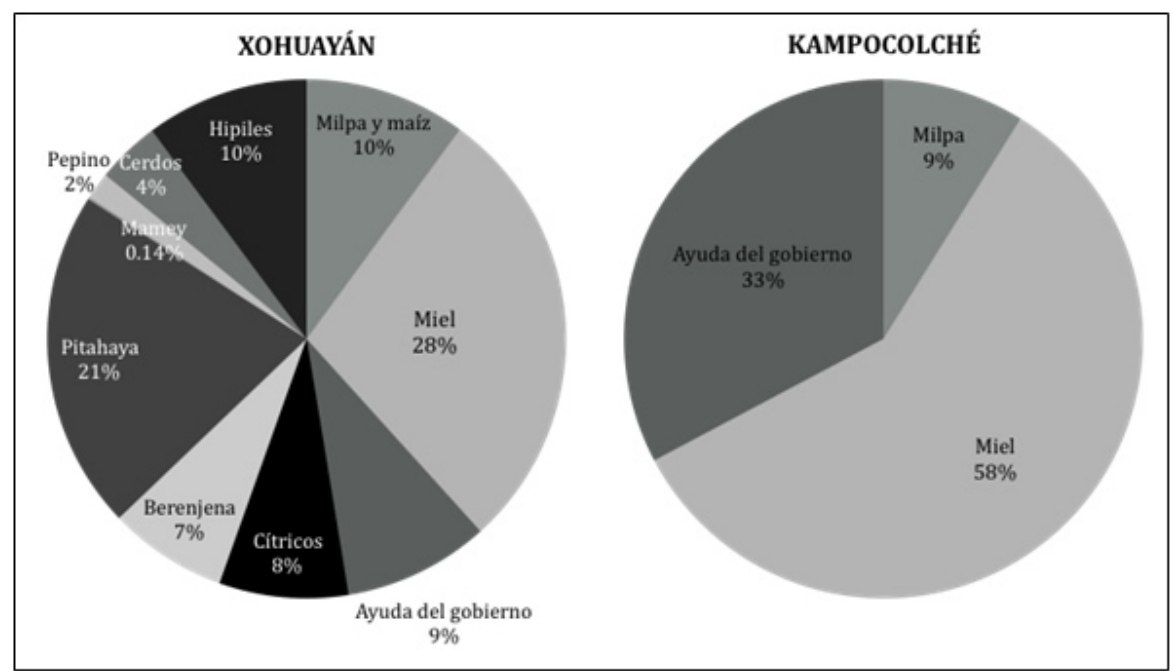

Figura 4. Distribución de las fuentes de ingresos de la unidad familiar tipo para cada comunidad Fuente: Elaboración propia

En otras regiones de México la ganaderización sí tuvo éxito, como lo reportan Lazos y Godínez (1996). En el ejido que ellas estudiaron el ganado permaneció pese a que la mayoría de los ejidatarios producían milpa y se permitió cercar áreas libremente, pues "la tierra era de todos los ejidatarios". Este acaparamiento modificó el uso de suelo comunitario al convertir en potreros la mitad de las mejores tierras cultivables.

\section{Del abandono de prácticas agroecológicas a LA MECANIZACión Y AL RiEgo de productos CON Fines COMERCiales en XohuAYÁn (YuCATÁN)}

La primera intervención clave para Xohuayán ocurrió en 1994, a partir de la llegada de un promotor de la escuela de agricultura ecológica U Yits Ka'an (se traduce de la lengua maya como "rocío del cielo"), apoyada por el Programa de las Naciones Unidas para el Desarrollo (PNUD) y de su Programa de Pequeñas Donaciones (PPD). La escuela es dirigida por sacerdotes católicos, técnicos y académicos de diversas universidades cuya corriente ideológica fue y sigue siendo la promoción de formas de vida sustentable de las familias campesinas. Los proyectos iniciales del técnico-promotor incentivaron la labranza de conservación, la cual es una técnica agroecológica que pretende el mantenimiento de la cobertura vegetal, evita el desgaste del suelo e incentiva la protección de la materia orgánica. La técnica incluye el arado con pico o incluso la no labranza, pero siempre se mantiene un residuo vegetal en la superficie (Violic, 1989). Un cambio trascendente que generó este proyecto en el territorio fue la sedentarización de la milpa, como lo explica un campesino de Xohuayán:

\footnotetext{
... en esa época no hay cítricos, no hay riego, nomás trabajamos en la milpa de la tumba (...)La idea cuando amanece es tumbar [cortar árboles] y chapear [limpiar la tierra de maleza y hierbas con el azadón] la milpa (...)Tenemos un chan [sic] poquito de ganado pero esa época los ganados sueltos pastan (...)En esa época toda la memoria de nosotros es trabajar de la milpa. Cuando vino [el promotor] (...) allá cambió porque di cuenta que la labranza aunque hagas un mecate [ $400 \mathrm{~m} 2]$ sacas hasta siete costales de elote, entonces allá dimos cuenta que no tiene caso que tengamos hasta cuatro hectáreas de monte alto. Mejor que hagamos hasta diez mecates de labranza mínima allá lo sacas siempre. Y no hay mucha chamba ahí. ¡Entonces allá se cambió! (Campesino de Xohuayán).
}

Esta intervención tuvo consecuencias en la distribución territorial y en las formas de producción.El abandono de milpa trashumante implicó la desaparición de la organización por rumbos de los grupos domésticos. En Yaxcabá, municipio de Yucatán, Pérez (1995) documentó el cambio de las actividades agrícolas y modos de producción por efecto de las políticas agrícolas. Al igual que en Yaxcabá (Pérez, 1995), 
los campesinos en Xohuayán dejaron atrás la organización por rumbos para la producción de maíz.En cambio, aprovecharon las ventajas de la mecanización y prefirieron parcelar los terrenos ejidales -aunque fuera de manera informal-, ya que la intensificación les proporciona mayores rendimientos con menos esfuerzo físico. Seis años después de este proyecto, los milperos decidieron modificar sus prácticas e incursionar en la producción del maíz mecanizado, que requiere del uso del tractor año con año. Los campesinos argumentan que el cambio hacia la mecanización fue su decisión, ellos se enteraron de la llegada de los tractores a una comunidad vecina y se propusieron iniciarla en superficies planas no pedregosas.

En 1988 los campesinos se dedicaban exclusivamente a la milpa, por lo que el territorio se distribuía 30\% milpa y 70\% monte alto. Para 1994, con la llegada de la labranza mínima y la consecuente sedentarización de la milpa, el área del monte alto se incrementó. En el año 2000 la tendencia de reducción continuó para dar paso al maíz mecanizado, el cual siguió aumentando a costa del monte alto y la milpa tradicional. En 2001 los campesinos incorporaron los potreros, que continuaron su expansión.De la misma manera, la unidad de riego para frutales y hortalizas aparece en 2005 y aumenta de tal forma que en 2015 es la unidad territorial más amplia (Figura 5).

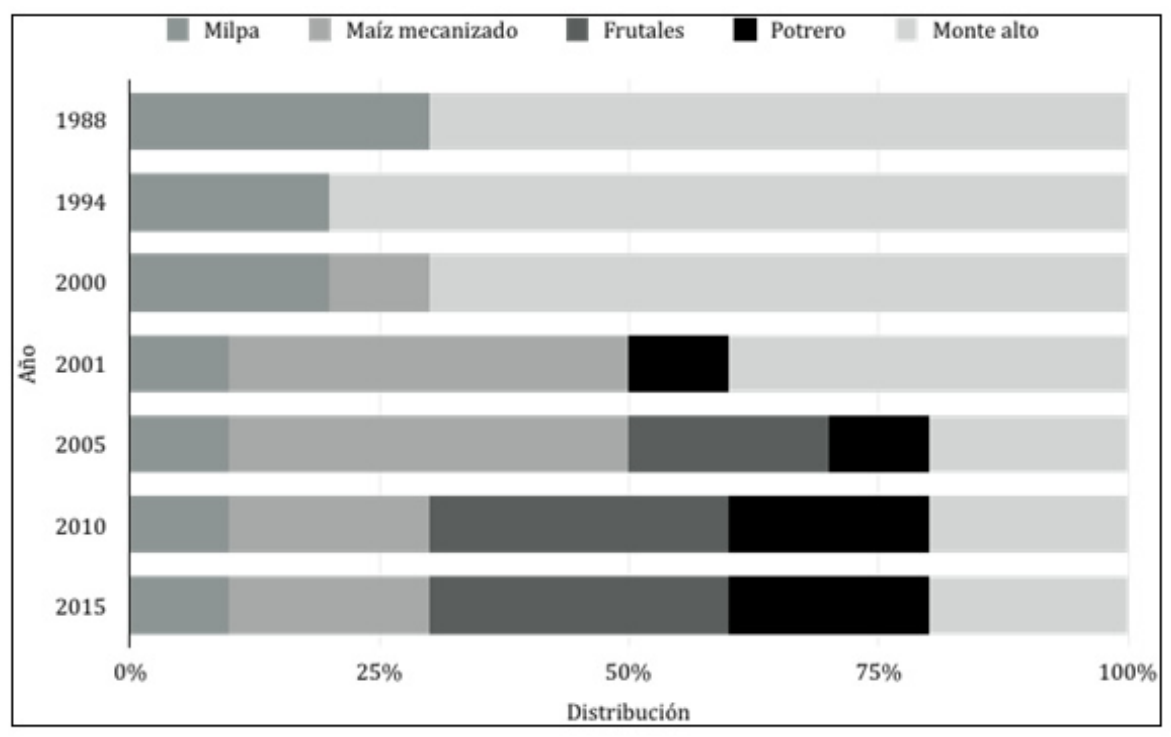

Figura 5. Cambio en la distribución de las unidades territoriales de Xohuayán, Yucatán según los propios campesinos (1988-2015) Fuente: Elaboración propia

Los campesinos de la comunidad recuerdan los objetivos de la labranza mínima y otras técnicas agroecológicas en relación al cuidado ambiental y describen detalladamente las técnicas que se llevan a cabo en estas alternativas productivas, sin embargo, lo describen como un proceso externo y atemporal para ellos:

La intención de la labranza mínima, dice el promotor, es para que no se siga tumbando el monte. Porque según dice el monte hay que cuidarlo porque son los árboles los que refinan el aire (...) si no hay ramas grandes dicen que el aire va a ser contaminado porque no hay árboles para purificar. La intención de ese promotor es no hacer tantas hectáreas de milpa, con diez mecates allá vas a tener tu comida. Entonces vi que hicimos la labranza mínima y vi que resultó muy bien. Aprovechamos las hojas que caen y [el estiércol del] cerdo para abonar. Enseñó cómo preparar algo de líquidos [ecológicos] para combatir las plagas (Campesino de Xohuayán).

Los campesinos mayas de Xohuayán explican que el abandono de la labranza se debió a un rompimiento en el grupo organizado y a que el rendimiento productivo del maíz mecanizado era suficiente para mantener el autoabasto familiar, pero con menor uso de mano de obra. El requerimiento de materia orgánica en la tierra, que en la labranza mínima lo proporcionaban las hojas secas y el estiércol de cerdos criollos, lo sustituyeron por estiércol de pollo proveniente de granjas intensivas. Así, los mayas toman decisiones acerca del sentido de 
la innovación socioambiental y danlugar a un proceso nuevo, diferente al proyecto pensado por los técnicos y a la estrategia tradicional.

La mecanización no fue la única intervención con evidentes cambios en el territorio. En 2005 inició el proyecto de instalación de la unidad de riego que modificó tanto la organización comunitaria como territorial, en conjunto con la reforma agraria de $1992^{3}$. Estos proyectos dieron paso a la propiedad privada de la tierra en Xohuayán. El riego fue instaurado por la Comisión Nacional del Agua (conagua) para impulsar la producción de cítricos y hortalizas, una continuación del Plan Chaac y el Plan Tabi de 1964 y 1975 en la región sur de Yucatán (Lazos, 1995a). A pesar de que el objetivo inicial de la intervención era potenciar el mercado de naranja dulce, los campesinos decidieron que los cultivos que implantarían fueran diversos y de elección familiar, así lo recuerda un productor de Xohuayán:

... la naranja hace como cinco años llega hasta 15 pesos la caja.Mi idea es sembrar para el consumo.Si hay para el mercado está bien, si no, para la familia. Cuando vengo a cosechar la berenjena llevo [a casa] mandarina, piña, toronja, pues si hay mucho lo bajo hasta diez cajas, pero la idea es consumirlo... (Campesino de Xohuayán).

Inicialmente esta estrategia pretendía disponer de alimentos variados para el autoconsumo familiar considerando el tipo de suelo disponible en cada parcela.Posteriormente, conforme observaron el comportamiento en la demanda y precios del mercado, los campesinos dieron preferencia a ciertos productos y modificaron sus propias prácticas de forma tal que los favoreciera en las ganancias.

En la figura 4 se aprecia la fuente de ingresos para Xohuayán, la cual se mantiene ampliamente diversificada, inclusive con cultivos que no proporcionan los mayores ingresos, como es el caso de los cítricos. Aunque en este caso proporcione $8 \%$ de los ingresos (entre limón, naranja, toronja y mandarina), los mayas deciden mantenerlos para el consumo familiar ocasional. Así también ocurre con cultivos que proporcionan menos del uno por ciento del ingreso como lo es el mamey, por lo que observamos una continua tensión entre mantener una diversidad para el consumo diario y especializarse para ser más productivos.

Acompañado de la mecanización, la intensificación y el riego, el cambio en la producción agrícola implicó el aumento en el uso de agroquímicos. En esta comunidad fertilizan el maíz con la mezcla 18-46-00 (N$\mathrm{P}-\mathrm{K})$.En las hortalizas usan el triple 17 (17\% para cada compuesto de N-P-K) y urea, mientras que como herbicida usan Paraquat, y como acaricida en la apicultura la flumetrina. Los campesinos con el tiempo han aprendido el uso de estos y otros compuestos, y los utilizan conforme les reditúe económicamente:

Alguien me dijo que había sembrado papaya, que le echaba Borox para que quedara dulce. Le puse en el tronco y fumigué una parte, porque hay para poner en suelo y en el aire, $i$ Y quedó muy dulce! Para fumigar la papaya hay un montón. Para que no entre el hongo. Apenas empiece a florecer hay que meterle Biozyme, P-K y aparte hay que meterle Manzate. Éste es un preventivo para hongos, pero no los cura; si ya tiene, no lo quita. Ahora para el hongo efectivo hay varios (...) Antes que nazca el maíz metemos belfosato y agramina. El belfosato mata al zacate, lo que no mata son bejucos. Por eso metemos la agramina para bejucos...

Este breve fragmento permite reconocer el amplio conocimiento empírico-técnico que los campesinos han adquirido e interiorizado en su práctica cotidiana, sin embargo, la dependencia de insumos importados es una práctica que no abona a la autosuficiencia de los agroecosistemas ni a su sostenibilidad.

\section{Del CAMBio EN LA SUBJETIVIDAD RELACIONADA A LA CRía DE CERDos EN LAS dos COMUNIDADES DE ESTUDIO}

Las intervenciones también cambiaron la representación que los campesinos mayas tenían de los cerdos criollos, criados en el traspatio en el sur de Yucatán. Tradicionalmente el cerdo criollo formaba parte del traspatio de las familias, sin embargo, en esta región la población actual de esta raza es muy baja. En Xohuayán, los campesinos recibieron varios apoyos del PNUD en conjunto con universidades locales, para aumentar la producción de cerdos de raza criolla que se alimentaban del frijol mucuna (Mucuna pruriens), producido 
con las técnicas de cultivos alternativos. En ocasiones posteriores, la comunidad de Xohuayán se ha visto apoyada por la escuela de agroecología cuyo objetivo era revalorar estos animales y conservar su genética.Se obtuvo un resultado diferente del esperado, ya que la consideración que tienen de ellos es que no justifican económicamente su mantenimiento. En esta comunidad, la cría de cerdos genéticamente mejorados ahora es vista como un negocio, ya que la venta de estos animales aporta $4 \%$ del ingreso de la comunidad (Figura 3).Por lo tanto, es necesario que la cría de los animales sea más eficiente, es decir, que crezcan rápido y al menor costo de alimentación. Así, los campesinos en esta localidad han descubierto que la raza criolla no responde a estas intenciones, sino que la cruza entre el cerdo americano y el cerdo criollo funciona mejor, ya que puede consumir alimento balanceado y maíz, al mismo tiempo que no requiere de aplicaciones de vacunas y reduce tiempo de crianza. Incluso ahora se tiene la representación de los cerdos criollos como un producto de exportación, es decir, que su costo de producción por tardar más en crecer sólo puede ser pagado por extranjeros, debido a que sólo ellos valorarían la calidad de los cerdos y pagarían un excedente, que no sería pagado por los miembros de la comunidad (Tabla 1 ).

Tabla 1. Propósitos de la cría de cerdos en Xohuayán y Kampocolché

\begin{tabular}{|c|c|}
\hline Xohuayán & Kampocolché \\
\hline $\begin{array}{l}\text {... ahorita tiene más apoyo los indios [cerdos } \\
\text { criollos]. Lo escuché en el radio y en el } \\
\text { periódico. Los gringos ahorita ven un cochino } \\
\text { indio criollo y lo compran (...) [un cerdo] de } \\
40 \text { o } 50 \text { kilos [vale] como cinco mil pesos. }\end{array}$ & $\begin{array}{l}\text {... nosotros estamos acostumbrados a } \\
\text { festejar novenas, de vez en cuando se mata } \\
\text { [un cerdo]. Ahora estamos criando como diez; } \\
\text { van a servirnos en enero, el seis de enero, es } \\
\text { el día de los tres santos reyes (...) Esta vez } \\
\text { tenemos que matar como } 14 \text { cochinos (...) } \\
\text { solamente yo con mis hijos tengo que matar } \\
\text { como ocho o nueve diario... }\end{array}$ \\
\hline $\begin{array}{l}\text {...no tanto nos conviene el americano, nos } \\
\text { conviene la cruza, porque se cría aquí en las } \\
\text { casas. Ni son pelones [criollos] ni son de } \\
\text { raza, son cruzas. Crecen más y engordan } \\
\text { también. Porque el valor que tienen los } \\
\text { criollos, los que son cerdos pelones [criollos] } \\
\text { es para los ricos (...) y como son criollos, } \\
\text { para ellos es mucho más bueno la carne que } \\
\text { la de la granja. Porque criando un cerdo } \\
\text { pelón te llevaría como un año para que llegue } \\
\text { de esta altura. Criando un cerdo de raza o de } \\
\text { granja a los dos meses que empezaste a } \\
\text { criar ya está de este tamaño. Puro químico, } \\
\text { inyecciones, alimentos, puro químico... }\end{array}$ & $\begin{array}{l}\text { No [no lo venden], es para nosotros, porque } \\
\text { nosotros hacemos fiestas y novenas (...) } \\
\text { Cuando sea grande el cochino es para servir } \\
\text { a la fiesta (...) Son de razas así antiguas. } \\
\text { Sólo maíz y de masa [respecto a que comen } \\
\text { los cerdos], a veces quedan unas tortillas se } \\
\text { les dan a los cerdos así. } \\
\ldots \text { el [cerdo] americano tiene que comprarle } \\
\text { alimentos, hay que comprarle su vacuna } \\
\text { también [no crían estos cerdos] (...) Hay } \\
\text { muchos tipos de hierbas que damos al } \\
\text { cochino [criollo] y maíz... }\end{array}$ \\
\hline
\end{tabular}

En Kampocolché la situación es diferente ya que la cría de la raza criolla continúa como parte de su modo de vida tradicional. Toda la comunidad cría cerdos criollos que son alimentados con insumos locales como el maíz y sus derivados, diversidad de hierbas que ellos mismos colectan en las zonas aledañas a los hogares y sobras de comida -como restos de frutas y hortalizas-. Por lo tanto, aunque su engorda tarda varios meses en terminar, no requieren de un desembolso de dinero en efectivo porque no demandan alimento balanceado comercial $\mathrm{u}$ otros insumos externos -como medicamentos o suplementos alimenticios- como en el caso de Xohuayán. Además, el reembolso de la inversión tampoco es en dinero ya que los cerdos no se venden,sino que se utilizan en platillos tradicionales que se acostumbran para las festividades religiosas comunitarias.

La valoración de la raza de estos animales es diferente en cada uno de los sitios de estudio.Mientras en Xohuayán se busca capitalizar su producción, en Kampocolché le asignan una función de ofrenda en las 
ceremonias religiosas y tratan que les cueste lo menos posible su mantenimiento (Tabla 1). Igualmente importante es el cambio en la apreciación que tienen de la raza criolla, pues en Xohuayán su valoración no es intrínseca de la conservación de la raza propia de la región, sino que queda subordinada al beneficio que otra clase social pague por él.

\section{DEL CAMBIO EN LA PRODUCCIÓN AGRíCOLA TRADICIONAL EN RELACIÓN A LAS EXIGENCIAS DEL MERCADO}

Para adaptarse a las demandas del mercado los campesinos en Xohuayán han modificado las prácticas productivas tradicionales, mientras que en Kampocolché perpetúan estas últimas. Ello se refleja en las actividades que realizan durante el año y que representamos en sus calendarios agrícolas (Figura 6).

Los miembros de la comunidad de Xohuayán han adaptado sus actividades agrícolas a los vaivenes del mercado, es decir, la decisión de las fechas de siembra y cosecha la determinan los precios y la disponibilidad de los compradores. Tal es el caso del limón y del frijol xpelón (Vigna unguiculata).Mientras el limón se cosecha en septiembre para que vuelva a florecer y se obtenga fruto en cuaresma, el frijol xpelón se siembra en agosto para cosechar en las festividades del día de muertos a finales de octubre. Intervenciones del PNUDy su programa PPDimpulsaron en 2002 la producción de pitahaya (Hylocereus undatus), que, como puede verse actualmente, proporciona $21 \%$ de los ingresos (Figura 3), y aunque la asesoría técnica no contemplaba el uso de fumigaciones con agroquímicos, los campesinos adquirieron conocimiento de su uso por cuenta propia para con ello alcanzar mejores rendimientos.

Al sistematizar el calendario agrícola del sur de Yucatán, Lazos (1995b) documenta que hace 23 años la cosecha principal de maíz ocurría en enero y la cosecha de calabaza en los primeros días de febrero. Así, en 1995 las extensiones de cultivo eran mayores.La brecha y la medición de los terrenos iniciaban a finales de agosto, ya que la roza y tumba se realizaba en vegetación de 20 años o más, y con vegetación menor a 15 años, estas actividades iban de septiembre a febrero. Estos cambios se deben a que en Xohuayán incorporaron las semillas mejoradas para el uso intensivo, mientras que en Kampocolché continuaron con la selección y preservación tradicional de sus semillas, pues sus campesinos consideran que ellas se adaptan a las condiciones edáficas (no dependen de agroquímicos) y son un legado de sus abuelos mayas.

Con las semillas mejoradas en Xohuayán la cosecha de los elotes ya no ocurre en enero, sino en noviembre, lo cual implica una mayor acumulación de trabajo en este mes. En cambio, en Kampocolché, donde mantienen las semillas heredadas de varias generaciones, el calendario se mantiene similar al reportado por Lazos (1995b), excepto en el inicio de la roza y tumba, que no ocurre en vegetación mayor a 20 años porque la mantienen como conservación voluntaria.

Resalta también la escala de valoración que los campesinos de Kampocolché pusieron a los meses.Ellos acopiaron los mejores meses de noviembre a mayo, dado que es el tiempo durante el cual se cosecha toda la fuente de su consumo, sea maíz, frijol, calabaza, lentejas, ibes, camote o jícama. Para los campesinos de Xohuayán, los mejores meses del año son junio, julio y agosto, dado que son los meses que obtienen mayores ganancias económicas en los cultivos agrícolas.Además, por las lluvias mantienen el pasto para alimentar el ganado, por lo que la importancia de la cosecha de elote y calabaza pasa a segundo plano.

El caso de la apicultura muestra un cambio importante, pues la disminución de monte en Xohuayán provocó que en el mes de enero no hubiera cosecha de miel de tajonal (Viguiera dentata) -flor característica de la región-, por lo que su calendario de cosecha de miel inicia recién a finales de febrero. En cambio, en Kampocolché está floración marca el inicio de la temporada de cosecha de miel y la principal fuente de ingresos para los apicultores en esta región. 


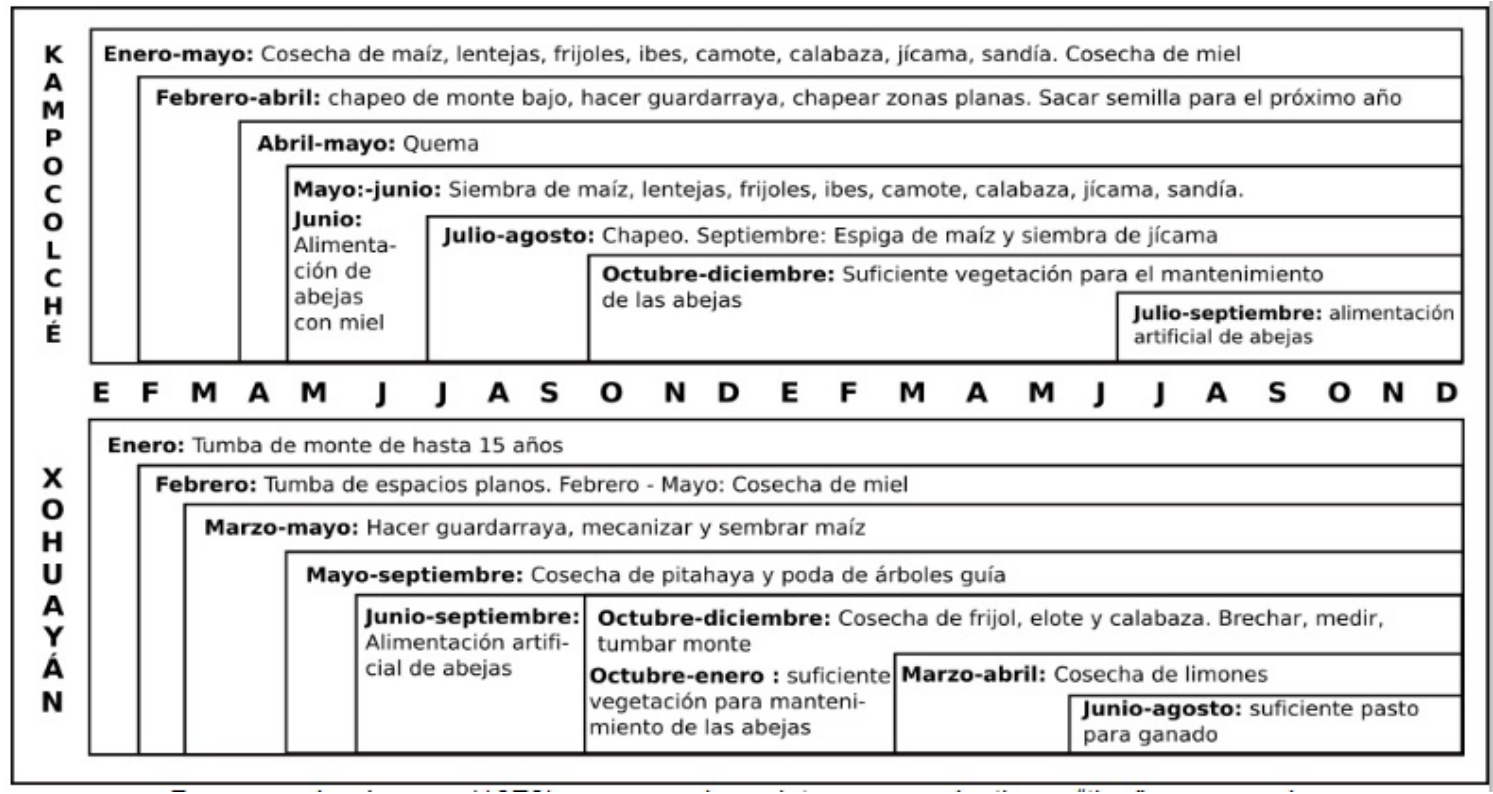

Figura 6. Calendario de actividades agrícolas y apícolas en Xohuayán y Kampocolché Fuente: Elaboración propia

\section{ESTRATEgIAS CAMPESINAS EN MODELOS DIFERENCIADOS: PROCESOS PRODUCTIVOS EN LOS CASOS DE ESTUDIO}

La figura 7, basada en el marco conceptual para el análisis del campesinado de Deere yde Janvry (1979), resume los sistemas productivos "tipo" para cada comunidad de estudio en esta investigación, a nivel de grupo doméstico. Deere yde Janvry (1979) elaboraron un marco teórico que identifica variables clave a ser evaluadas en tres niveles: la organización (que incluye procesos de producción, circulación y reproducción), los mecanismos de extracción de excedentes y la diferenciación de clases entre campesinos. En el caso de la presente investigación ponemos énfasis en los procesos de producción, y no se detallan los procesos de diferenciación de clase ni de reproducción. Además, los medios de producción se clasifican de acuerdo al tipo de capital, lo cual permite incluir los capitales social y humano, que no se consideraban en los análisis económicos.

A partir de estrategias productivas los campesinos mayas transforman sus capitales disponibles en productos con valor de uso y valor de cambio.A su vez, estos últimos se incorporan a distintos tipos de mercado. El ganado bovino, porcino e hipiles bordados se venden en la misma localidad o en localidades aledañas, mientras que las hortalizas y frutos se comercializan en centros de acopio de las cabeceras municipales y posteriormente son trasladados por los acopiadores a las principales ciudades de la península de Yucatán. Como producto de exportación dirigido al mercado europeo, la miel se vende a intermediarios o, en algunos casos, a cooperativas que luego se encargan de vendérsela a los exportadores. El ingreso de dinero en efectivo que proporcionan estas actividades permite a los campesinos el acceso a medios de consumo, medios de trabajo y materias primas para mantener los procesos de reproducción de la unidad doméstica.

Los capitales son los recursos disponibles para los campesinos, definidos por Bourdieu (2001) como el trabajo acumulado en sus diferentes expresiones; son los medios de vida que serán transformados mediante diversas actividades en bienes y servicios. En Xohuayán y Kampocolché el capital humano está conformado por la conjunción del conocimiento local y el conocimiento técnico de los campesinos que contribuyen a mantener y mejorar sus actividades agropecuarias.Lo definimos como la amalgama entre el conocimiento empírico que poseen sobre el territorio, la agricultura tradicional y el manejo de los recursos naturales, y el conocimiento transmitido por técnicos en cursos de capacitación e intercambio de experiencias para aumentar la productividad agrícola, mejorar la calidad de los suelos o aumentar los volúmenes e inocuidad de la miel convencional y orgánica; también han recibido capacitación en relación a la conservación de la selva. 


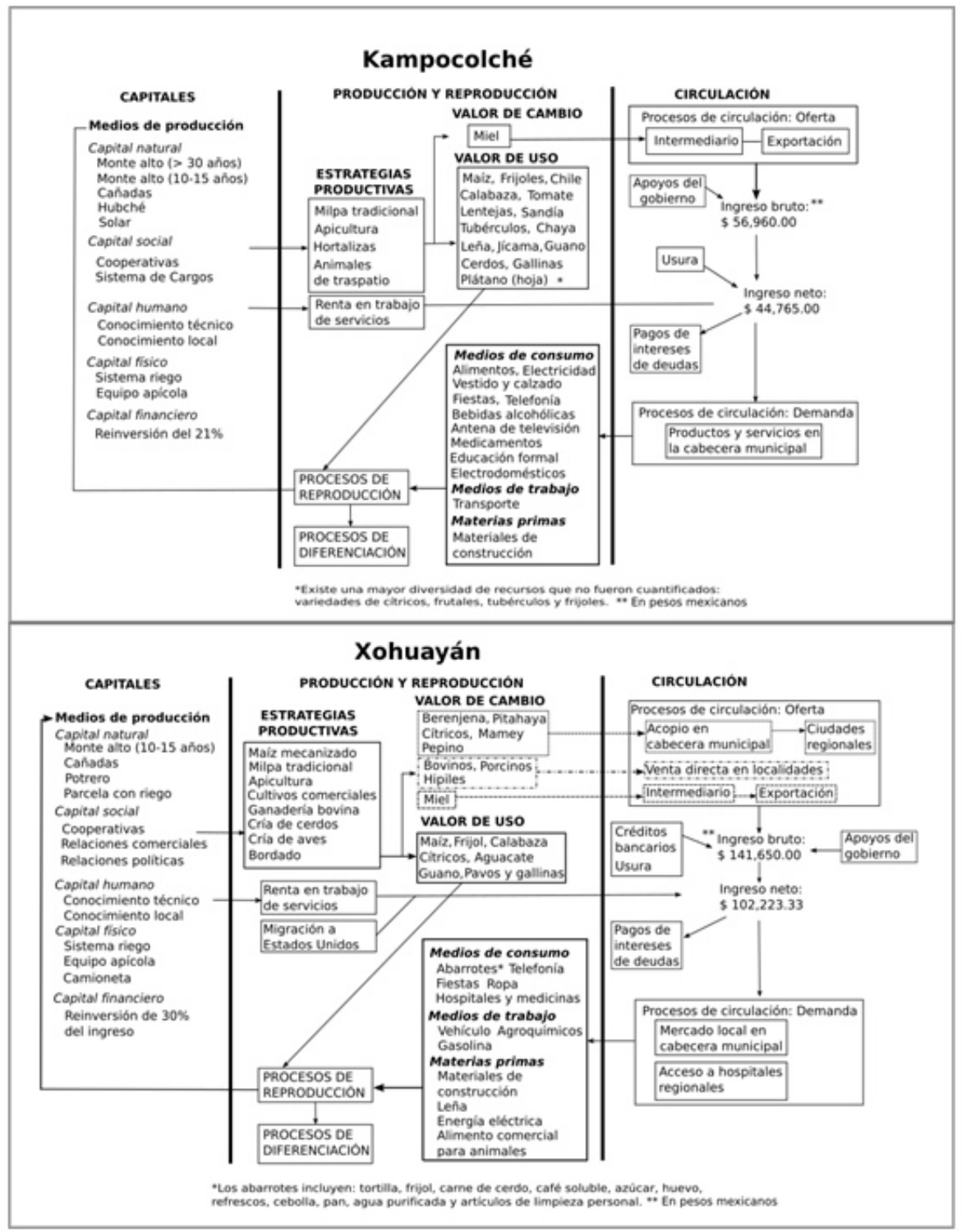

Figura 7. Estrategias productivas a nivel de grupo doméstico usadas por las comunidades para obtener productos comerciales y de autoabasto

Fuente: Elaborado con base en Deere y de Janvry (1979) e información de campo

El capital social se conforma por las cooperativas de miel y de transporte creadas para obtener mejores precios para los productos -al reducir intermediarios-, y para acceder a apoyos gubernamentales y créditos bancarios. Otras formas de organización que contribuyen con la creación de capital social son los comités religiosos, las comisarías municipales y ejidales. En el caso de Xohuayán, también identificamos la unidad de riego, conformada por socios con acceso a parcelas que cuentan con ese servicio, y en Kampocolché distinguimos el mantenimiento de la organización por cargos originada durante la denominada "Guerra de Castas" de 1847 que establece jerarquías y turnos para adorar a la Cruz Parlante ${ }^{4}$. La organización por cargos ha ido cambiando con los años pero aún permanece para coordinar festividades religiosas y para guardar el santuario de la Cruz Parlante en la cabecera municipal.

En Xohuayán el capital físico se conforma de la infraestructura del sistema de riego (que incluye las bombas, mangueras y microaspersores) y la inversión de los campesinos en la compra de camionetas y motocicletas, mientras que en Kampocolché esta especie de capital se constituye por una infraestructura mucho menos sofisticada, porque allí los campesinos no poseen vehículos ni motocicletas (utilizan principalmente bicicletas) y las herramientas usadas en la agricultura son típicas de la región desde hace varios años.Sin 
embargo, en esta última comunidad destacan las carreteras en buen estado que los comunican con la cabecera municipal.

El capital natural en Xohuayán está conformado por diferentes unidades territoriales, sea monte alto de 10 a 15 años, las "cañadas" -que son terrenos planos-, los potreros y la parcela de riego para cultivos mercantiles. En Kampocolché el monte permite el mantenimiento de la milpa tradicional y terrenos en diferentes tiempos de descanso.Además, en los traspatios o solares cercanos a las viviendas cultivan una diversidad de hortalizas y árboles frutales.

Ambas comunidades han obtenido el capital financiero de la reinversión de la venta de productos al mercado, de programas sociales e intervenciones de diferentes instituciones. En Xohuayán la diversificación permite la obtención de dinero en efectivo a partir de la venta de ganado, la venta de frutas, hortalizas e hipiles -ropas tradicionales de mujer elaboradas por ellas-, y quienes no poseen terrenos con riego venden su mano de obra a quienes poseen ese capital. En Kampocolché, el ingreso monetario proviene de la venta de la miel y de los programas sociales. Los ingresos permiten a estas comunidades acceder a medios de consumo, de trabajo y materias primas para mantener los procesos de reproducción familiar, al mismo tiempo que generan procesos de diferenciación de clase social entre los campesinos, los cuales son más marcados en Xohuayán a raíz del modelo de desarrollo elegido. Si bien los ingresos permiten la satisfacción de necesidades básicas, existen diferencias cualitativas: mientras en Kampocolché tienen acceso a vestido y calzado básico, en Xohuayán acceden a joyas y variedad de zapatos y ropas. Igualmente, mientras en Kampocolché las fiestas se enfocan principalmente en la comida, en Xohuayán adquieren un gusto suntuoso por los adornos y otros bienes complementarios.

\section{Conclusiones}

Los cambios en los modos de vida de los campesinos en la península de Yucatán son resultado en parte de las intervenciones generadas por la cooperación internacional. Ya Giménez (1995) había anticipado los cambios en la configuración cultural del país y su identidad a partir de la apertura de los tratados internacionales para el intercambio de mercancías. Sin embargo, algunas comunidades indígenas tienen modos de vida particulares en los cuales las transformaciones a partir de la modernización no se ajustan.

Kampocolché es lo que Barceló (2006) llamaría un sistema de bienes autorreproducibles. El sistema productivo y económico en dicha comunidad está compuesto por varios subsistemas, todos ellos autárquicos, pues dependen mayormente de la fuerza de trabajo de los campesinos, de insumos locales como sus semillas guardadas año con año y de herramientas rústicas. Igualmente, sus procesos reproductivos dependen de sus productos con valor de uso.Esto es un elemento económico interpretado como un mecanismo de resistencia al sistema hegemónico de mercado, pues regula principios sociales dentro de la comunidad como la reciprocidad, en oposición a la acumulación capitalista (Varese, 1986).

El proceso de modernización y globalización ha penetrado más en Xohuayán. Allí los campesinos tienen el control de su tierra, el control de su trabajo y una ventaja competitiva dentro del mercado, lo que les permitemantenerse con ingresos por encima de la línea de pobreza. Sin embargo, como vemos en el esquema integrativo, es un sistema abierto que depende de insumos externos para su reproducción, como las semillas mejoradas, los fertilizantes sintéticos, los herbicidas, plaguicidas, la extracción de grandes volúmenes de agua, alimento balanceado y abono orgánico. Aun así, no han abandonado del todo el control de sus procesos socioproductivos y tampoco ha significado la extinción de su cultura, sino que ha ocurrido lo que Giménez (1995) llamó modernización reagregativa, pues los campesinos de esta comunidad se apropiaron de las racionalidades modernas a partir de su propia identidad cultural. La transición hacia la modernización que ocurre en el sistema agroalimentario completo, en Xohuayán cambia su lógica hacia una de un incremento productivo: producir más a un menor costo de mano de obra, invertir en insumos y reinvertir las ganancias. 
En Xohuayan hay un proceso de modernización, tanto material como subjetivo, que ocurre mediante la apropiación de algunos elementos culturales, lo cual permite obtener un modo de vida más cómodo a costa de la dependencia política y la vulnerabilidad económica. En cambio, en Kampocolché tienen un modo de vida apegado a la tradición maya, y rehúyen del control político y la modernización con base en sus elementos culturales autónomos.

Los pueblos indígenas tienen el derecho a la autodeterminación y por ello ambas comunidades han seguido rutas de desarrollo diferentes de acuerdo a sus intereses comunitarios y familiares. Sin embargo, no se puede dejar de lado que el sistema económico capitalista se expande y permea en las economías de los campesinos indígenas. En este sentido el presente artículo contribuye a hacer visible la existencia de comunidades con modelos alternos al sistema imperante.

\section{Agradecimientos}

A las profesoras Erin Estrada y Aremy Evangelista, y al profesor Eduardo Bello; por sus comentarios que enriquecieron este trabajo.

\section{Bibliografía}

Baños, O. (2001). La modernidad rural mexicana a fines de milenio: El caso de Yucatán. México, Mérida: Universidad Autónoma de Yucatán.

Barceló, A. (2006). Nota sobre Pasinetti, los bienes autorreproducibles y el "factor" trabajo. Revista de Economía Critica, 5, 89-101.

Bonfil, G. (1991). La teoría del control cultural en el estudio de los procesos étnicos. Estudios sobre las Culturas Contemporáneas, 4(12), 165-204.

Bonfil, G. (1995). Etnodesarrollo: sus premisas jurídicas, políticas y de organización. En Obras escogidas de Guillermo Bonfil Batalla, Tomo 2 (pp. 467-480). México: INAH / INI.

Bourdieu, P. (2001). Poder, derecho y clases sociales (2da ed.). España: Desclée de Brouwer.

Deere, C. \& de Janvry, A. (1979). A Conceptual Framework for the Empirical Analysis of Peasants. American Journal of Agricultural Economics, 61(4), 601-611.

Diario Oficial de la Federación (21 de mayo de 2014). Decreto por el que se reforman, adicionan y derogan diversas disposiciones del reglamento de la Ley General del Equilibrio Ecológico y la Protección al Ambiente en Materia de Áreas Naturales Protegidas. Diario Oficial de la Federación. México. Recuperado de http://www.dof.gob.mx $/$ nota_detalle.php?codigo $=5345530 \&$ fecha $=21 / 05 / 2014$

Dumond, Don E. (2005). Elmachete y la cruz. La sublevación de campesinos en Yucatán. México: Universidad Nacional Autónoma de México.

Elizondo, C., y López, D. (2009). Las áreas voluntarias de conservación en Quintana Roo. Serie acciones núm. 6, México: Comisión Nacional para el Conocimiento y Uso de la Biodiversidad. Recuperado de http://era-mx.org/biblio /Elizondo_AVC.pdf.

Ellis, E.A., Hernández, I.U., y Romero, J.A. (2017). Los procesos y causas del cambio en la cobertura forestal de la Península Yucatán, México. Ecosistemas, 26(1), 101-111.

Ellis, E.A. \& Porter, L. (2008). Is community-based forest management more effective than protected areas? A comparison of land use/land cover change in two neighboring study areas of the Central Yucatan Peninsula, Mexico. Forest Ecology and Management, 256, 1971-1983.

Escobar, A. (1995). Encountering Development. The making and unmaking of the third world through development. United States of America, New Jersey: Princeton University Press. 
Estrada, E.I.J., Bello, E., y Velazco, S.J. (2011). Milpa, conocimiento local y organización social del espacio. En E. Bello et al (Ed.), Cultivar el territorio maya: Conocimiento y organización social en el uso de la selva (pp. 99-131). México: El Colegio de la Frontera Sur, Universidad Iberoamericana.

Giménez, G. (1995). Modernización, cultura e identidad social. Espiral, estudios sobre Estado y Sociedad, 1(2), 35-56.

Graddy-Lovelace, G. (2017). The coloniality of US agricultural policy: articulating agrarian (in)justice. The Journal of Peasant Studies, 44(1), 78-99.

INEGI. (2010). Marco Geoestadístico. Disponible en Instituto Nacional de Estadística y Geografía: http:// www.inegi.org.mx/geo/contenidos/geoestadistica/m_geoestadistico.aspx

Lazos, E. (1995a). Del maíz a la naranja en el sur de Yucatán: auge y dinámica de la huerta 1. En E. Hernández et al (Ed.), La milpa en Yucatán: un sistema de producción agricola tradicional (pp. 527-563). México: Colegio de Postgraduados.

Lazos, E. (1995b). La milpa en el sur de Yucatán: dinámica y crisis 1. En E. Hernández et al (Ed.), La milpa en Yucatán: un sistema de producción agrícola tradicional (pp. 565-607). México: Colegio de Postgraduados.

Lazos, E., y Godínez L. (1996). La familia como estructura productiva en el inicio de la ganadería en tierras campesinas del sur de Veracruz. En Estudiar a la familia, comprender a la sociedad (pp.107-189). México: Sistema Nacional para el Desarrollo Integral de la familia (DIF), Universidad Nacional Autónoma de México (UNAM), Universidad Autónoma Metropolitana (UAM).

Long, N. (2007). Sociología del desarrollo. Una perspectiva centrada en el actor. México: Centro de Investigaciones y Estudios Superiores en Antropología Social, El Colegio de San Luis.

Marañón, B. (2012). La colonialidad del poder y la economía solidaria: Apuntes para la reflexión teórico-metodológica del Grupo de Trabajo Economía Solidaria. En B. Marañón (Ed.), Solidaridad Económica y potencialidades de transformación en América Latina: Una perspectiva descolonial (pp. 21-58). Buenos Aires, Argentina: CLACSO.

Mignolo, W. (2005). “Un paradigma otro”: Colonialidad global, pensamiento fronterizo y cosmopolitanismo crítico. Dispositivo, 25(52) 127-146.

Pérez, M.L. (1995). Unidades de producción y estrategias de reproducción económica (pp. 455-484). En E. Hernández et al (Ed.), La milpa en Yucatán: un sistema de producción agricola tradicional. México: Colegio de Postgraduados.

Quijano, A. (1992). Colonialidad y modernidad/racionalidad. Perú indigena, 13(29), 11-20.

Varese, S. (1986). Multietnicidad y construcción hegemónica: proyectos indios y futuro global. La palabra y el hombre, 57, nueva época, 23-40.

Violic, A. (1989). Labranza convencional y labranza de conservación: Definición de conceptos. En H. Barreto et al (Ed.), Labranza de conservación en maiz: documento de trabajo del curso especializado Labranza de Conservación (pp. 5-11). México: CIMMYT/PROCIANDINO.

Waldmueller, J. (2015). Agriculture, knowledge and the 'colonial matrix of power': approaching sustainabilities from the Global South. Journal of Global Ethics, 11(3), 294-302.

Warman, A. (1985). Estrategias de sobrevivencia de los campesinos mayas. Cuadernos de investigación social, número 13, México: Universidad Nacional Autónoma de México.

Weber, J., y Reverte, J.P. (2006). La gestión de las relaciones sociedades-naturaleza: modos de apropiación y derechos de propiedad. Revista de Geografía Agricola, 36, 119-124.

\section{Notas}

1 “Milpa es un espacio donde se derribó selectivamente el monte y se establecieron las plantas cultivadas; también es el conjunto de cultivos asociados al maíz, la planta más importante del complejo; y se le llama hacer milpa al proceso de trabajo que implica desde la selección del monte que se va a tumbar hasta la recolección de los frutos para iniciar el descanso que permite la regeneración de la vegetación natural” (Warman, 1985, p. 10).

2 Las áreas destinadas voluntariamente a la conservación de acuerdo a las leyes mexicanas (Diario Oficial de la Federación, 21 de mayo de 2014) hacen referencia a zonas de las que particulares (organizaciones, grupos, pueblos indígenas, etc.) son dueños y hacen uso bajo diferentes manejos, y que proveen de servicios ambientales como son el mantenimiento de 
la biodiversidad, la provisión de agua o el mantenimiento del equilibrio en los ciclos ecológicos naturales. Los pagos por estos servicios son mecanismos económicos que pretenden el mantenimiento de estas áreas a cambio de un beneficio económico.

3 En 1992 se reformó en México el artículo 27 de la Constitución, a partir de lo cual se permitió la compra y venta de terrenos ejidales, con el propósito de incentivar la inversión privada en el campo mexicano y dar certeza jurídica a los compradores de los terrenos.

4 La "Guerra de Castas" tuvo sus causas en los abusos que sufrieron los mayas por parte de las clases sociales superiores -ya que tanto el estado como la Iglesia se excedieron en impuestos y trabajo-, y fue incentivada por el odio de los indígenas hacia los blancos (Dumond, 2005). 